\title{
POLÍTICAS DE COMUNICACIÓN PARA LA IMPLEMENTACIÓN DE LOS ACUERDOS DE PAZ EN COLOMBIA
}

\author{
Communication policies for the implementation of peace agreements in Colombia
}

Juan Carlos Garzón Barreto ${ }^{1}$

\section{Resumen}

En 2016, el gobierno de Colombia y la guerrilla de las FARC-EP suscribieron el "Acuerdo final para la terminación del conflicto y la construcción de una paz estable y duradera”. En dicho instrumento las partes formalizaron compromisos en materia de medios y servicios de comunicación. Sin embargo, se debe establecer si los acuerdos de paz realmente lograron resolver las necesidades estructurales de democratización de lo comunicacional en Colombia. También es necesario identificar los posibles obstáculos para la implementación de los acuerdos de paz en su materia comunicacional. Con el propósito de abordar estos puntos, se realiza una revisión en tres sentidos: se exponen breves antecedentes sobre las demandas de comunicación de los movimientos alzados en armas en Colombia; se valora el alcance de los acuerdos de paz en materia de comunicaciones y se plantean algunas coordenadas de acción estatal para la implementación de los compromisos adquiridos; por último se ofrecen algunas conclusiones.

\section{Palabras clave}

Acuerdos de paz, democratización de medios, políticas de comunicación, negociación, demandas comunicacionales, movimiento armado.

\section{Abstract}

In 2016, the government of Colombia and the FARC-EP guerrillas signed the "Final agreement for the end of the conflict and the construction of a stable and lasting peace". In this instrument, the parties formalized commitments regarding communication media and services. However, it must be established if the peace agreements really managed to resolve the structural needs of democratization of communication in Colombia. It is also necessary to identify possible obstacles for the implementation of peace agreements in their communication matter. In order to address these points, a review is carried out in three senses: brief background information is presented on the communication demands of the movements raised in arms in Colombia; the scope of the peace accords in the area of communications is valued and some coordinates of state action are proposed for the implementation of the acquired commitments; Finally, some conclusions are offered.

\section{Keywords}

Peace agreements, democratization of media, communication policies, negotiation, communication demands, armed movement.

\footnotetext{
${ }^{1}$ Universidad Distrital Francisco José de Caldas (Colombia) y Universidad Externado de Colombia. Correo electrónico: jcgarzonb@gmail.com
} 


\section{Antecedente sobre demandas de comunicación de los movimientos alzados en armas en Colombia}

Comprender el contexto y el contenido de las demandas históricas en materia de comunicación, paz y democracia en Colombia, permitirá determinar si los acuerdos de paz logrados entre el gobierno y las FARC-EP, se corresponden con tales expectativas. Estos podrían además constituir los antecedentes de futuras reformas estatales y la fuente de orientaciones en materia de políticas y acciones sobre paz, comunicación y democracia en Colombia.

\subsection{Las demandas de comunicación del movimiento Jorge Eliécer Gaitán Ayala, JEGA.}

Para empezar y por brindar un marco histórico, en primer lugar, se acude a las razones mediáticas ofrecidas en la declaración mediante la cual se anunció la creación del movimiento Jorge Eliécer Gaitán Ayala, JEGA, a finales de los años 80 del siglo XX. Dicho documento fue recogido por la Revista Semana (agosto de 1989), en los siguientes términos:

Ante la tumba de Gaitán, según testigos, juraron que vengarían su muerte. Uno de los párrafos del manifiesto decía: "Cansados de no ser escuchados en nuestros deseos de practicar la democracia. Huérfanos de quienes fueron asesinados por haber sido partidarios del líder popular Jorge Eliécer Gaitán, usurpados en nuestros derechos, por habérsenos defraudado en las elecciones de 1970 cuando Misael Pastrana Borrero usurpó la Presidencia de la República que con nuestros votos habíamos conquistado para el general Rojas Pinilla, marginados de las elecciones porque ser representantes del pueblo implica disponer de un inmenso capital, víctimas del silencio de la prensa y demasiado pobres para contar con los medios que implica editar un diario propio, hemos tomado el único camino que nos permite combatir a esta oligarquía que ha hecho que, como dijera Gaitán, los ricos sean cada día más ricos y los pobres cada día más pobres.

Los términos de la declaración anterior, permiten advertir dos de los problemas estructurales (históricos), en materia de democratización de los medios en Colombia. De una parte, la concentración de la propiedad de los medios en manos privadas. De otra, la falta de garantías para que los partidos de oposición puedan acceder a los medios de comunicación en condiciones de equidad, con el objeto de desarrollar sus expectativas de participación política y electoral. A la fecha de divulgación de la declaración del
JEGA, febrero de 1987, tal tipo de demandas en materia de democratización de las comunicaciones en Colombia, ya habían sido rubricadas a sangre y fuego, precisamente, en el contexto de los hechos luctuosos de la toma del Palacio de Justicia, en noviembre de 1985.

\subsection{ElM-19y las demandas de comunicación.}

En segundo lugar, los guerrilleros de la compañía Iván Marino Ospina del M-19 que desarrollaron la llamada: "Operación Antonio Nariño por los Hombres", eran portadores de un conjunto de demandas en materia de acceso a las comunicaciones, las cuales fueron reproducidas por la Revista Semana (diciembre 1985). A continuación, algunos fragmentos:

Es falso que la paz haya fracasado en Colombia. Han fracasado estruendosamente los sectores y personas que han querido reducirla al tamaño de sus mezquinos intereses, pero la paz sigue teniendo la dimensión de la Patria, la grandeza de la aspiración de los pueblos. (...) Primero: Que en los periódicos citados: El Tiempo, El Espectador y El Siglo de Bogotá, El Colombiano y El Mundo de Medellín, El Pueblo y El País de Cali, Vanguardia Liberal, de Cundinamarca, Diario del Caribe y El Heraldo de Barranquilla, y La Patria de Manizales, el gobierno haga públicos los documentos que aparecen a continuación, en el orden, sitio y tamaño aquí especificados. Primer día: La publicación de esta proclama y del texto de los acuerdos firmados en Hobo, Corinto y Medellín el 24 de agosto de 1984 entre el gobierno y el M-19 y el EPL, ocupando una página entera en la primera sección. (...)

Segundo: La divulgación, por dos cadenas radiales de cubrimiento nacional dentro del espacio de sus noticieros nacionales, de esta proclama en su texto exacto y completo, durante los cuatro días en que se realicen las publicaciones exigidas en el punto anterior. (...)

Tercero: La creación de un espacio radial diario, de duración de una hora, en tiempo de clasificación A, usando una cadena radial de cubrimiento nacional para que los colombianos todos, a través de nuestras organizaciones gremiales, cívicas, deportivas, sindicales, comunitarias, planteemos la respuesta a estas dos preguntas: a). ¿Cuál es su exigencia más apremiante? y b). ¿Este gobierno le ha cumplido?

Las demandas contenidas en el texto del comunicado que el M-19, que divulgó en el contexto de los hechos del Palacio de Justicia, da cuenta de tres situaciones a resolver en materia de democratización de las comunicaciones en Colombia: la prensa está en manos privadas, el gobierno de turno controla los medios de radiodifusión, y las organizaciones de la sociedad civil carecen de acceso a 
los medios de comunicación social controlados por el gobierno.

Para comprender con mayor claridad la situación de control gubernamental de los medios de comunicación en la Colombia de los años 80 del siglo XX, basta con citar las actuaciones que el Informe de la Comisión de la Verdad sobre los hechos del Palacio de Justicia, (Gómez, Herrera y Pinilla, 2010), atribuye a la Ministra de Comunicaciones de la época, Nohemí Sanín Posada:

\section{4. (...) Otros periodistas también se comunicaron con el magistrado Reyes Echandía, después de lo cual la Ministra de Comunicaciones llamó a Yamid Amat, a Juan Gossaín y a Juan Guillermo Ríos y les dijo que si seguían pasando estas entrevistas o noticias del Palacio, se cerrarían todos los noticieros.}

109. Hacia las 6:00 o 7:00 p. m., el periodista Yamid Amat recibió la llamada de la ministra Sanín, quien le ordenó interrumpir la transmisión. Ella le dijo que aun cuando no había resolución, era una orden. Él dijo que lo haría si los demás medios lo hacían. Ella le replicó que, si no interrumpía, le ordenaba al Ejército que se tomara la emisora y apagara los transmisores, y le ordenó transmitir un partido de fútbol. Los silenciaron y los obligaron al fútbol. No les permitieron emitir siquiera boletines. Yamid Amat consideró esto como una implacable imposición de censura. La Ministra le dijo tiempo después que esa era "la única manera de salvar la democracia". 110. "La censura tuvo como efecto la muerte de la Corte. [...]. Los medios de comunicación eran en ese momento los ojos abiertos, y les colocaron una venda. Eran la única luz de información que tenía el gobierno; cuando vino la censura, no sabían qué estaba pasando", concluyó Yamid Amat. 111. En entrevista con la Comisión de la Verdad, sin embargo, la exministra Sanín negó categóricamente la versión anterior" (pp. $133-140$ ).

Los hechos narrados por la Comisión de la Verdad, dibujan los peligros que entraña para una democracia el hecho de que los medios de comunicación estén sometidos al control desbordado del poder ejecutivo, regentado por los gobiernos de turno.

\subsection{La propuesta de François Mitterrand, la Constituyente de 1991 y la democratización de las comunicaciones.}

En el contexto de los debates de la Asamblea
Constituyente de 1991 en Colombia, se puso sobre la mesa la idea de reestructurar los poderes del Estado para tener organismos independientes de regulación de los medios, como lo había propuesto el Presidente François Mitterrand, en su carta a los franceses en 1988. En efecto, la idea de crear organismos autónomos e independientes para la regulación de las comunicaciones, encuentra un gran antecedente en la "Comisión de la comunicación y la libertad", propuesto por Miterrand en su "carta a los franceses"; documento mediante el cual expresa su intención de crear un poder que esté al nivel de los más altos poderes del Estado, constituyéndose como un cuarto poder para el manejo autónomo de la radiodifusión. Con esta iniciativa, el Miterrand aseguró que "Montesquieu, a distancia, puede alegrarse de que un cuarto poder se ha unido a los otros tres y dio a su teoría de la separación de poderes el mayor tributo de nuestro siglo" ${ }^{\text {. }}$.

En Colombia, en las 29 ponencias presentadas y en las conclusiones de las mesas preparatorias de la Asamblea Constituyente de 1991, se abordó una buena parte de las demandas y las discusiones sobre paz, medios y democracia, hasta entonces registradas en el país, incluidas las de un sector del movimiento armado que se había desmovilizado por aquellos años, y al cual el gobierno de la época le dio un noticiero. Luego con la Ley 335 de 1996, otro gobierno liberal intentó frenar el acceso de la oposición a la televisión. Diversos ciudadanos demandaron dicha Ley. El asunto fue desatado por el Tribunal Constitucional en la Sentencia C-350 de 1997².

\subsection{La comunicación y las propuestas de la Coordinadora Guerrillera Simón Bolívar - CGSB-.}

Para continuar con las demandas del movimiento armado, en tercer lugar, debe recordarse que la llamada Coordinadora Guerrillera Simón Bolívar, creada en 1987, la cual integró originalmente a las FARC, el M-19, el ELN, el EPL, el Partido Revolucionario de los Trabajadores y el Movimiento Armado Quintín Lame, se refirió a las comunicaciones, en los documentos emanados de su VI Cumbre (Medina Gallego, 2012). En efecto, en las denominadas: "Doce propuestas para construir una estrategia de paz", documento divulgado por la Coordinadora Guerrillera Simón Bolívar en 1992, las organizaciones que aún no se habían desmovilizado, consignaron: "Noveno. Colombia necesita una democracia sin trampas, sin estatutos antiterroristas que solo golpean

\footnotetext{
${ }^{1}$ Mitterrand, François. "Carta a los franceses”. Tomado de: http://miroirs. ironie.org/socialisme/www.psinfo.net/entretiens/mitterrand/1988lettre. html.

2 República de Colombia. Corte Constitucional. Sentencia C-350 de
} 
a la oposición y a los inconformes, sin privilegios para los poderosos de los medios de comunicación, sin militarización de las campañas electorales y con una Registradora del estado Civil como rama independiente del poder público" (p. 455).

\subsection{El Ejército Popular de Liberación - EPL- y sus demandas de comunicación.}

Para explicar los orígenes del Partido Comunista Marxista-Leninista de Colombia y del Ejército de Liberación Popular - EPL, Frank Molano Camargo (2015) escribe:

\begin{abstract}
El PC ML fue organizado a mediados de la década de 1960, como resultado de los debates entre líneas políticas diferentes en el Partido Comunista (...) Los militantes que habían sido expulsados o se habían retirado del PCC buscaron formas de reagrupamiento organizativo entre 1963 a 1965, llegando a acuerdos con otros grupos de la "nueva izquierda": el MOEC, el FUAR, PRS, la Juventud del MRL e incluso un sector de la revista democristiana "La Nueva Prensa" (...) Estos sectores formarán el Comité de Integración de los Movimientos Revolucionarios Colombianos CIMREC, que desde un principio se trazó como tarea la construcción de un nuevo partido marxista leninista.
\end{abstract}

A propósito de los sectores que Molano reconoce como parte de dicha nueva izquierda, resulta de interés resaltar la posición y reivindicación del llamado Movimiento MOEC- (1965), frente a la actuación de los medios en el país:

\begin{abstract}
A la clase oligárquica de Colombia le parece que nuestra sociedad tal como está es aceptable y lógica (...) A través de la "gran prensa" y todo su aparato propagandístico confunde al pueblo con versiones mentirosas sobre los acontecimientos diarios y ensalza a los verdugos más deshonestos e inmorales de su fauna dirigente. (...) El enemigo explotador, desde el poder y con los medios de divulgación, educación y propaganda en sus manos, no ceja en su intento de deformar la conciencia de nuestro pueblo. (...) De lo que sucede en el parlamento se entera el pueblo a través de las informaciones suministradas por los aparatos propagandísticos de la burguesía. Así las voces democráticas del escasísimo número de parlamentarios progresistas que se pueda colar al Congreso, son ahogadas por las toneladas de mentiras de las grandes rotativas y demás medios publicitarios del régimen.
\end{abstract}

Estos planteamientos del MOEC, refuerzan la idea de

1997. http://www.corteconstitucional.gov.co/relatoria/1997/C-350-97. $\underline{\mathrm{htm}}$ que en la Colombia de mediados del siglo XX, los medios de comunicación se encuentran ligados a la estrategia de poder de los sectores oligárquicos. De allí que tales sectores de izquierda reivindiquen la necesidad de acceso a los medios.

Aun cuando el EPL surge en $1965^{3}$, y se reintegra a la vida civil en 1991, la visión que sobre las comunicaciones han tenido estos sectores, se ha mantenido en el tiempo ${ }^{4}$. Así, al caracterizar la "Formación económico-social de Colombia" las líneas trazadas en la década pasada por el XVI Congreso del Partido Comunista de Colombia Marxista-Leninista de 2007, ha señalado que:

\begin{abstract}
La ofensiva ideológico-cultural del imperialismo va de la mano de su política neoliberal, pretende ordenar todos los espacios de la vida cultural y personal de los pueblos según sus intereses. El uso de los medios de comunicación, de los desarrollos de las ciencias y del arte busca anular la conciencia revolucionaria, fragmentar a las masas, negar sus valores y castrar su espíritu creativo y de protesta. Esto le exige al Partido una intensa lucha en este terreno, capacidad para formular alternativas, defender lo cultural, la historia, los valores populares, los espacios colectivos, además de desarrollar creatividad para hallar los medios más variados para lograrlo.
\end{abstract}

Sobre el proceso de reintegración de la guerrilla del EPL a la vida civil, escribe Molano (2015): "En 1990 sufrió una nueva división, cuando el 90\% del partido y del EPL se desmovilizaron y entraron a conformar el movimiento Esperanza Paz y Libertad. Desde entonces subsiste una pequeña estructura partidaria con una cada vez menor influencia social y una estructura militar debilitada, con presencia en la zona del Catatumbo".

No obstante, la histórica y frondosa artillería verbal de este sector Marxista - Leninista, en relación con las demandas de democratización de las comunicaciones en Colombia, el texto oficial de los requerimientos y acuerdos logrados entre el gobierno y el Ejército Popular de Liberación -EPL (febrero 15 de 1991), en su proceso de desmovilización para entrar en la Constituyente de 1991, se contrae a peticiones internas de la organización, relativamente modestas:

\footnotetext{
3 VILLARRAGA SARMIENTO ÁlVARO. Centro Nacional de Memoria Histórica. El Ejército Popular de Liberación. EPL. http://centrodememoriahistorica.gov.co/descargas/CatedraBY/ presentaciones/Sesion-4/Presentacion-EPL.pdf

4 ROJAS, ERNESTO. Comandante del EPL (1987). NOTAS DE COMANDANCIA SOBRE LA HISTORIA DEL EPL. Tomado de: https:// goo.gl/7wL5LW
} 
"PROMOCIÓN DEL PROCESO DE PAZ. I. Publicidad. A). El Gobierno financiará la publicación de una página en cuatro diarios de circulación nacional y tres diarios de circulación regional, de un texto cuyo contenido y fecha de publicación serán responsabilidad del Ejército Popular de Liberación. Igualmente, el Gobierno financiará un segundo aviso de página en dos diarios de circulación nacional en fecha que decidirá el EPL y con texto que será de su responsabilidad, con el objeto de presentar al país las propuestas que tiene esta organización para la Asamblea Nacional Constituyente. B). El Gobierno se compromete a promover el proceso de negociación y los avances en las tareas de reinserción a través de un programa especial de televisión que será transmitido en el espacio habitual de la programadora "Audiovisuales". La Consejería contratará los servicios técnicos y profesionales necesarios para la realización de dicho programa, cuyo guión será preparado por el equipo contratado y el EPL. C). Con el objeto de asegurar la mayor sintonía al programa especial de Audiovisuales, La Consejería contratará tres avisos pequeños, consecutivos, en un diario de circulación nacional, informando el título, fechas y hora de la emisión. (...) F). El Gobierno apoyará la edición de un libro de 3.000 ejemplares sobre la historia del EPL en el proceso de paz, cuyo texto será responsabilidad de esa organización.

PROMOCIÓN DEL PROYECTO POLÍTICO. Con el propósito de contribuir a la publicidad del Proyecto Político derivado del Proceso de Paz adelantado por el EPL, y de señalar su definitiva conveniencia para el desarrollo y fortalecimiento de la democracia colombiana ante la sociedad en general, el Gobierno Nacional se compromete a financiar: A). La publicación de un aviso de página entera en día dominical o festivo a criterio del EPL, en dos diarios de circulación nacional y cinco de circulación regional, con texto que será de responsabilidad del EPL. B). La emisión de mensajes sobre el desarrollo del Proceso de Reinserción y del proyecto político futuro del EPL, a razón de uno por cada campamento y de dos por semana, en la franja que en la televisión colombiana tiene el programa "Amarillo, Azul y Rojo", que serán financiados por el Gobierno Nacional y preparados por el equipo técnico de la programadora de Audiovisuales y el profesional que se contrate por la Consejería para el mismo fin, y C). A la producción y emisión de dos programas adicionales a través de la programadora Audiovisuales para que se transmita en la franja institucional en el horario normal, en fecha que acordarán las partes".

Realmente, estos compromisos puntuales que el EPL suscribió con el gobierno, en su proceso de desmovilización, no están encaminados a introducir transformaciones que conduzcan a la democratización de las comunicaciones en Colombia. Adicionalmente, resulta paradójico que el libreto de actuación del EPL en la votación de la Constituyente de 1991, en lo relacionado con la creación de un ente autónomo para el manejo de la televisión en Colombia, fue muy confuso. Uno de los dos delegados del EPL se abstuvo de votar favorablemente una propuesta muy similar a la que el propio presidente François Mitterrand consideraba progresista en 1988. La iniciativa de crear un ente autónomo para regular la televisión en Colombia, fue mayoritariamente votada por los miembros de la Asamblea Constituyente de 1991, con la abstención del EPL (Garzón Barreto, 2015).

Al comparar los acuerdos logrados en 1991 por el EPL, en relación con el acuerdo suscrito en 2016 entre el Gobierno y las FARC-EP, 25 años después, se aprecian grandes diferencias, toda vez que las FARC- EP, sin tocar los grandes ejes para la democratización de las comunicaciones en Colombia, no sólo reclama acceso a los medios para su propio movimiento, sino que amplía su abanico de compromisos a otras organizaciones de la sociedad civil.

\subsection{Las comunicaciones y la concepción programática del II Congreso de la UC-ELN.}

En lo que corresponde a la comprensión de los medios de comunicación, por parte del Ejército de Liberación Nacional, Medina Gallego (2012), al referirse a los contenidos del programa elaborado por el II Congreso Nacional de la UC-ELN, desarrollado entre octubre y noviembre de 1989, señala que: "En la concepción de la UC-ELN, hacen igualmente parte del bloque dominante, el bipartidismo, las fuerzas armadas, los medios de comunicación, así como la jerarquía eclesiástica” (p. 516).

La propuesta que plantea el programa del II Congreso Nacional de la UC-ELN, en relación con los medios de comunicación, según Medina Gallego (2012), está íntimamente ligada a sus reflexiones y críticas frente al denominado socialismo real:

\footnotetext{
"Dada el estado de burocratización en que se encuentran los países del socialismo real, la UC-ELN propone establecer un sistema de control popular y revolucionario y de revocabilidad del mandato que impida la burocratización y garantice el funcionamiento eficaz del nuevo estado. Existe en este planteamiento un quiebre esencial, que refleja la crítica al modelo histórico de una sociedad socialista de partido único y una fuerte burocracia estatal que determina el devenir político y económico de la nación y que se plantea una sociedad multipartidista y pluralista y construida sobre
} 
el ejercicio del poder y la democracia popular. Por último, se propone hacer de los medios de comunicación verdaderos instrumentos del ejercicio de la libertad democrática, poniéndolos al servicio de la educación, la cultura y la expresión política y libre de todo el pueblo" (p.520) (resaltado nuestro).

Frente a los planteamientos referidos del Ejército de Liberación Nacional, en relación con los medios de comunicación, se aprecia que identifican el gran poder ideológico de este sector del bloque de poder; la necesidad de regular los privilegios para los poderosos medios y el propósito de democratizar las comunicaciones para que sus usos más sociales permitan avanzar hacia la sociedad pluralista.

\subsection{La Plataforma de un gobierno de reconstrucción y reconciliación nacional y las demandas de comunicación de las FARC-EP.}

Como cuarto y último elemento sobre demandas de comunicaciones del movimiento armado en Colombia, se recordará el planteamiento realizado en los años 90 del siglo XX por las FARC-EP (1993). Así, en abril de 1993, la Octava Conferencia Nacional de Guerrilleros, la cual era la máxima instancia de las FARC-EP, adoptó un documento de 10 puntos, nominado: "Plataforma de un Gobierno de reconstrucción y reconciliación nacional". En lo relacionado con el alcance de las demandas en materia de comunicaciones, se consignó:

3. Participación democrática nacional, regional y municipal en las decisiones que comprometen el futuro de la sociedad. (...) La oposición y las minorías tendrán plenos derechos políticos y sociales, garantizándoles el Estado su acceso a los grandes medios de comunicación. Habrá libertad de prensa (...).

De conformidad con lo anterior, se aprecia que la demanda de las FARC-EP en materia de comunicaciones se contrae, fundamentalmente, al acceso de la oposición y las minorías políticas a los medios de comunicación. Así mismo, las FARC-EP recogen, con fervor revolucionario, la bandera que Rafael Núñez y Miguel Antonio Caro, les habían dejado en el artículo 42 de la Constitución Política de Colombia de 1886: "Habrá libertad de prensa" (Garzón Barreto, 2017a).

Nada dicen las FARC-EP sobre los derechos a la expresión, la información ${ }^{5}$ y la comunicación ${ }^{6}$ que son el gran objeto de debate sobre la regulación de lo comunicacional en el mundo. Tampoco dicen mucho las FARC-EP sobre demandas y políticas comunicacionales hacia el futuro, pues, en su reciente documento de trabajo denominado: "Tesis preparatorias del congreso fundacional del partido de las FARC-EP - marzo de 2017”. El referido documento ideológico y programático no hace una sola alusión a políticas de prensa, radio, televisión, internet, y telecomunicaciones.

La única alusión que el documento borrador para la creación del nuevo partido de las FARC-EP (mayo de 2017), hace sobre lo comunicacional, se encuentra contenida en la tesis No. 36. "Balance preliminar de la reincorporación en lo político". Concretamente se informa que: "Se ha aprobado por otra parte, el acto legislativo que regula la creación de nuestro partido político legal y las condiciones de su accionar, incluida la participación electoral, la financiación y el acceso a medios de comunicación".

Este breve balance de los antecedentes de las demandas y reivindicaciones armadas y ciudadanas, en relación con las comunicaciones, la paz y democracia, demuestran que estas aspiraciones son históricas y tienen claras finalidades estructurales para el desarrollo de la democracia. Si bien es cierto, las FAR-EP y el ELN, coinciden frente a la necesidad de contar con acceso a los medios para el libre juego democrático y para darle espacio a la sociedad civil. Es perfectamente claro también que el ELN, al igual que las FARC-EP, entiende la necesidad de: "una de democracia sin trampas (...) sin privilegios para los poderosos de los medios de comunicación", conforme las demandas conjuntas de la Coordinadora Guerrillera Simón Bolívar -CGSB-; pero, en los acuerdos suscritos por las FARC$\mathrm{EP}$, este elemento se desvanece completamente.

En los acuerdos suscritos por las FARC-EP en materia de comunicaciones, ciertamente, dicha reivindicación

\footnotetext{
${ }^{5}$ Ver Corredoira, L. y Sánchez, R. (2016). Qué es y qué no es derecho a la información. Dificultad metodológica de la consideración histórica de la información por la diversidad de sus parámetros de observación. En: Cetina, R., Corredoira, L. y Gutiérrez, R. (Eds.) Informar: ¿Derecho o deber? ¿De qué hablamos cuando hablamos del derecho a informar? Itala. 2016 IAMCR Conference. FIÉDI - LEICESTER2016. Universidad Complutense de Madrid. España. Disponible en: http://eprints.ucm. es/39990/

${ }^{6}$ Para ampliación del debate sobre la regulación de lo comunicacional en el mundo, consultar Garzón Barreto, JC. (2017). Colombia: transformaciones de lo comunicacional y reconfiguración del derecho de la comunicación. Ponencia presentada al Congreso de la Asociación Internacional de Estudios en Comunicación Social. IAMCR/AIECS 2017. Cartagena - Colombia. Julio de 2017.
} 
de equilibrar la balanza mediática en Colombia, es absolutamente ausente. Las FARC-EP reclaman un poco de la mermelada digital y mediática para su nueva agrupación y para algunas organizaciones de la sociedad civil, sin tocar los privilegios de los poderosos medios de comunicación, ni otras reformas estructurales prioritarias para democratizar las comunicaciones y las tecnologías de la información en Colombia.

Hasta aquí algunos elementos para la contextualización histórica de las demandas que han de fundamentar las políticas y las acciones estatales, en materia de comunicaciones, para la implementación de los acuerdos de paz con las FARC-EP, en Colombia.

2. El alcance de los acuerdos de paz en materia de comunicaciones y las coordenadas de acción estatal para la implementación

Cuando se examina el texto del acuerdo de paz suscrito entre el gobierno y las FARC-EP, en lo que corresponde a las comunicaciones, es dable examinar sus contenidos en tres perspectivas. Primero. Los acuerdos de paz y las demandas históricas sobre la democratización de las comunicaciones. Segundo. Las necesidades puntuales del proceso y los compromisos suscritos en materia de comunicaciones. Tercero. Las coordenadas de acción estatal para la implementación de los acuerdos sobre comunicaciones.

\subsection{Los acuerdos de paz y las demandas históricas sobre la democratización de las comunicaciones.}

Como se había anticipado en la contextualización histórica, el libreto programático de las FARC-EP en materia de comunicaciones gira en torno a tres puntos, a saber: i) el acceso genérico de la oposición política, las minorías y las organizaciones de la sociedad civil a las comunicaciones; ii) la satisfacción de las expectativas particulares de acceso de la organización fariana a los medios; iii) la declaratoria en favor de la libertad de prensa.

No obstante, esas demandas y expectativas de las FARCEP sobre lo comunicacional y la construcción de la paz y la democracia, se acomodan más a las reivindicaciones clásicas sobre medios, poder y propaganda política que alguna vez emergieron en la teoría de la Constitución de Loewenstein (Garzón Barreto, 2017b). Esa concepción y final negociación fariana, dejó por fuera otros aspectos estratégicos y urgentes para la reconfiguración de un modelo comunicacional democrático para una paz estable y duradera. Así, entre otros, nada se discutió y acordó sobre los controles estatales a los aberrantes niveles de concentración económica, cruzada y horizontal, de la propiedad de los medios en Colombia, por parte de los sectores económicos industriales y financieros. Estudios recientes así lo demuestran ${ }^{7}$.

Se ignoró en absoluto, la urgente necesidad de crear organismos reguladores, técnicos, autónomos, e independientes de los gobiernos de turno y de los poderes económicos y políticos dominantes, para el control de los medios y las telecomunicaciones. Como ya se ha mencionado, dicha necesidad ya había sido expuesta hace casi 30 años por el Presidente François Miterrand", a los socialistas en el mundo. Más recientemente, la propia Organización para la Cooperación y el Desarrollo Económicos (OCDE) $)^{9}$, le recomienda a Colombia este inaplazable ajuste institucional (Garzón Barreto y Neira Parra, 2017).

Otro asunto estratégico de creación de condiciones para la paz que se dejó por fuera de la agenda de negociaciones y acuerdos en materia de comunicaciones, fue la inaplazable decisión estructural de quitarle el control de los medios públicos a los gobiernos nacionales, regionales y locales de turno, para entregarle el manejo de estos operadores públicos a entidades estatales descentralizadas, técnicas, autónomas e independientes de las mayorías transitorias.

Los operadores públicos deben ser medios estatales para el fortalecimiento de la democracia nacional, regional y local, y no agencias capturadas por los clientelismos de turno, las cuales consumen el grueso de los recursos públicos del sector que son generados con el esfuerzo

\footnotetext{
7 Según lo presentado por FECOLPER - REPORTEROS SIN FRONTERAS DE ALEMANIA. (2015) en el Monitoreo de la Propiedad de Medios. MOM - Media Ownership Monitor. Bogotá D.C. Publicado en: http://www.monitoreodemedios.co/grupos-mediaticos/

8 MITERRAND, François. "Carta a los franceses". Tomado de: http://miroirs.ironie.org/socialisme/www.psinfo.net/entretiens/ mitterrand/1988lettre.html Cita original del Francés: "Montesquieu, à distance, pourra se réjouir de ce qu'un quatrième pouvoir ait rejoint les trois autres et donné à sa théorie de la séparation des pouvoirs l'ultime hommage de notre siècle".

${ }^{9}$ Ver Garzón Barreto JC., y Neira Parra, I. (2017). Panorama de las leyes y políticas de comunicación en Colombia en la última década. Las principales coordenadas históricas de la libertad de expresión en el constitucionalismo colombiano. En proceso de edición - Universidad Nacional de Colombia. "Lo curioso de todo este asunto es que a solicitud del propio gobierno colombiano la Dirección de Ciencia, Tecnología e Industria de la OCDE, realizó el "Estudio sobre políticas y regulación de telecomunicaciones en Colombia", cuyos resultados fueron presentados en abril de 2014 por Anne Carblanc, Jefe de la
} 
industrial de las empresas privadas. Este debate es urgente para la democracia y el uso adecuado de los recursos públicos del sector.

Es encomiable que los acuerdos de paz sobre comunicaciones se hubieran ocupado de demandar capacitación y dignificación para los trabajadores de los medios comunitarios, pero, se ha dejado por fuera la urgente tarea de establecer un régimen laboral y prestacional que garantice estabilidad y dignificación al trabajo de todos los trabajadores de la comunicación en Colombia, particularmente, estableciendo la llamada "cláusula de conciencia" que se acuñó en el contexto de la Constitución española de $1978^{10}$ para garantizar la libertad e independencia periodística y emancipar a los comunicadores de los grandes medios, en su calidad de trabajadores de la verdad.

Tendrá que reconocerse que el acuerdo encaminado a promover ajustes en la normatividad para introducir criterios de transparencia, objetividad y equidad en la asignación de la pauta oficial, en los niveles nacional, departamental y municipal, le apunta a corregir un aspecto estratégico para el saneamiento del circuito democrático. Una decisión de dicha naturaleza corrige las relaciones anómalas entre el poder político y el papel independiente que corresponde a los medios, particularmente, en la fiscalización de la gestión pública y en la garantía del equilibrio informativo para todos los partidos en el desarrollo de la contienda electoral.

En suma, y como se describirá en el siguiente acápite,

División de Comunicaciones, y Ángel Gurría, Secretario General de la Organización para el Desarrollo y la Cooperación (OCDE), quienes criticaron la excesiva intervención de funcionarios del Gobierno en los organismos reguladores y la escasa independencia de los mismos".

10 La Constitución española de 1978. "Artículo 20. Se reconocen y protegen los derechos: a) A expresar y difundir libremente los pensamientos, ideas y opiniones mediante la palabra, el escrito o cualquier otro medio de reproducción. b) A la producción y creación literaria, artística, científica y técnica. c) A la libertad de cátedra. d) A comunicar o recibir libremente información veraz por cualquier medio de difusión. La ley regulará el derecho a la cláusula de conciencia y al secreto profesional en el ejercicio de estas libertades. El ejercicio de estos derechos no puede restringirse mediante ningún tipo de censura previa. La ley regulará la organización y el control parlamentario de los medios de comunicación social dependientes del Estado o de cualquier ente público y garantizará el acceso a dichos medios de los grupos sociales y políticos significativos, respetando el pluralismo de la sociedad y de las diversas lenguas de España. Estas libertades tienen su límite en el respeto a los derechos reconocidos en este Título, en los preceptos de las leyes que lo desarrollen y, especialmente, en el derecho al honor, a la intimidad, a la propia imagen y a la protección de la juventud y de la infancia. Sólo podrá acordarse el secuestro de publicaciones, grabaciones y otros medios de información en virtud de resolución judicial". Tomado de: https://goo.gl/jdGZOQ los acuerdos logrados en materia de comunicaciones profundizan el acceso de las minorías y la oposición a los medios públicos como reivindicación histórica. Además, obtienen otros compromisos puntuales del Estado y saludan la libertad de expresión, pero no resuelven aspectos fundamentales como el control al poder del gobierno y a la concentración desmedida de medios privados.

\subsection{Necesidades puntuales del proceso y los compromisos suscritos en materia de comunicaciones.}

En primer lugar, en lo que corresponde a las necesidades operativas de comunicación para la implementación del proceso de paz, el gobierno y las FARC-EP, acordaron en el texto del documento final, el diseño de una serie de estrategias y herramientas comunicacionales asociadas a los mecanismos transitorios de coordinación y el desarrollo de sus tareas puntuales.

Dentro de estas medidas puntuales, se pueden contabilizar las 20 emisoras en FM, de interés público y de clase "C" que se le asignaran al operador público Radio Televisión Colombiana-RTVC-, para que operen en las en las zonas más afectadas por el conflicto. Lo que más preocupa de este asunto es que, incluso las emisoras de la radio nacional de Colombia, tienen serias dificultades de disponibilidad de recursos en su actual modelo de financiamiento.

Tabla 1. Frecuencia de alusión a los medios o servicios de comunicaciones en los acuerdos de paz suscritos entre el Gobierno de Colombia y las FARC-EP

\begin{tabular}{|c|c|c|c|c|c|c|}
\hline No. & Término & Frecuencia & RTVC $^{*}$ & Tema 1. & Tema 2. & Tema 3. \\
\hline 1 & Televisión & 6 & 4 & $\begin{array}{l}\text { Canal de } \\
\text { TV cerrada } \\
\text { para partidos } \\
\text { políticos. }\end{array}$ & $\begin{array}{l}\text { Espacio } \\
\text { en el canal } \\
\text { institucional. }\end{array}$ & \\
\hline 2 & Radio & 6 & 4 & $\begin{array}{c}\text { Convocatorias } \\
\text { de radio } \\
\text { comunitaria. }\end{array}$ & $\begin{array}{l}\text { Emisoras de } \\
\text { radio en las } \\
\text { zonas. }\end{array}$ & \\
\hline 3 & Internet & 2 & & $\begin{array}{c}\text { Infraestructura } \\
\text { y acceso } \\
\text { comunitario y } \\
\text { rural. }\end{array}$ & 0 & \\
\hline 4 & Telecomunicación & 0 & 0 & 0 & 0 & \\
\hline 5 & Prensa & 3 & 0 & $\begin{array}{c}\text { Oficinas de } \\
\text { prensa. }\end{array}$ & $\begin{array}{l}\text { Declaraciones } \\
\text { de prensa. }\end{array}$ & $\begin{array}{c}\text { Prensa como } \\
\text { fuente. }\end{array}$ \\
\hline 6 & Canales & 11 & 0 & $\begin{array}{c}\text { Acceso a } \\
\text { espacios en } \\
\text { canales y } \\
\text { emisoras en los } \\
\text { niveles nacional, } \\
\text { regional y local. }\end{array}$ & $\begin{array}{l}\text { Espacios en } \\
\text { los canales } \\
\text { y emisoras } \\
\text { de interés } \\
\text { público / abrir } \\
\text { espacios en } \\
\text { las emisoras } \\
\text { y canales } \\
\text { institucionales } \\
\text { y regionales. }\end{array}$ & $\begin{array}{l}\text { Otros usos / por } \\
\text { los canales más } \\
\text { indicados (8). }\end{array}$ \\
\hline
\end{tabular}




\begin{tabular}{|c|c|c|c|c|c|c|}
\hline 7 & Emisoras & 11 & 6 & $\begin{array}{l}\text { Mecanismos } \\
\text { de rendición } \\
\text { periódica de } \\
\text { cuentas (...) } \\
\text { incluyendo } \\
\text { emisoras } \\
\text { comunitarias. }\end{array}$ & $\begin{array}{l}\text { Emisoras } \\
\text { para la } \\
\text { reconciliación } \\
\text { (6). Ya estaban } \\
\text { contabilizados } \\
\text { en los otros } \\
\text { enunciados } \\
\text { con la palabra } \\
\text { radio. }\end{array}$ & \\
\hline 8 & Comunicación & 87 & & $\begin{array}{l}\text { Medios de } \\
\text { comunicación } \\
\text { (19) }\end{array}$ & $\begin{array}{l}\text { Otros usos } \\
\text { de la palabra } \\
\text { comunicación. }\end{array}$ & $\begin{array}{c}\text { Tecnologías de } \\
\text { la información } \\
\text { y las } \\
\text { comunicaciones }\end{array}$ \\
\hline 9 & Tecnologia & 8 & & $\begin{array}{c}\text { Tecnologias de } \\
\text { la información } \\
\text { (4) }\end{array}$ & $\begin{array}{l}\text { Telemedicina / } \\
\text { biotecnologia } \\
\text { / ciencia y } \\
\text { tecnologia. }\end{array}$ & MINTIC (1) \\
\hline 10 & Medios & 64 & & $\begin{array}{c}\text { Asociado a } \\
\text { medios locales, } \\
\text { comunitarios, } \\
\text { regionales y de } \\
\text { comunicación } \\
(26)\end{array}$ & $\begin{array}{l}\text { Medios de } \\
\text { producción. }\end{array}$ & $\begin{array}{l}\text { Por sus propios } \\
\text { medios y otros }\end{array}$ \\
\hline
\end{tabular}

Fuente: elaboración propia con base en el texto del acuerdo final para la terminación del conflicto y la construcción de una paz estable y duradera. Noviembre 24 de 2016. *Radio Televisión Nacional de Colombia - Operador público nacional de radio y televisión.

El anterior aspecto no será objeto de mayor análisis. Sin embargo es preciso advertir que, al igual que lo relacionado con la integralidad de los acuerdos, se desconoce con certeza, el cálculo real de los costos, las fuentes de financiamiento, así como no se han precisado las entidades que incluirán la respectiva contratación y el desarrollo de las tareas convenidas, en sus planes y presupuestos anuales. El manejo especial de estos aspectos técnicos de planeación, financiación, presupuestales y de contratación pública, será fundamental para la adecuada y oportuna implementación de los acuerdos.

En segundo lugar, los aspectos del acuerdo que corresponden a demandas y compromisos de comunicaciones con vocación de permanencia, en algunos casos abordan asuntos generales y, en otros, se concentran en actividades puntuales en algún sector. Para examinar la profundidad y el alcance de los acuerdos de paz, en materia de comunicaciones, resultará de utilidad hacer la lectura de la siguiente tabla de frecuencia.

Para efectos de la revisión puntual del texto de los acuerdos en materia de comunicaciones, en la tabla anterior, se acudió a rastrear la frecuencia, sentido y alcance del uso de algunos términos relacionados con lo comunicacional, que se estiman como relevantes a la hora de diseñar, implementar y evaluar políticas de comunicaciones.

Así, por ejemplo, se aprecia que en las 310 páginas del texto del acuerdo suscrito ${ }^{11}$, si bien es cierto, se compromete al Gobierno para: "promover la democratización de la

11 República de Colombia. Acuerdo final para la terminación del conflicto y la construcción de una paz estable y duradera. Gobierno de Colombia - FARC-EP. Bogotá. Noviembre 24 de 2016. Página 46. https://goo.gl/ZdtLYW información y del uso del espectro electromagnético disponible", el término "telecomunicaciones" no se menciona ni una sola vez en el acuerdo. La expresión "espectro electromagnético" solo se incluye una vez en el texto. Al respecto, debe recordarse que los procesos de información y comunicación no solo se soportan en el uso del espectro electromagnético sino en otras actividades relacionadas con el manejo de las redes y servicios, precisamente, de telecomunicaciones.

La palabra "televisión" es mencionada seis veces en los acuerdos, cuatro de estas para referirse al operador público RTVC, y los dos restantes para referirse, de una parte, a un canal cerrado para los partidos políticos, y de otra parte, a que se brinde espacios en el canal institucional en el marco de la implementación de los acuerdos.

El término "canales" se menciona en once oportunidades para referirse al "Acceso a espacios en canales y emisoras en los niveles nacional, regional y local": Los "Espacios en los canales y emisoras de interés público"; y para "Abrir espacios en las emisoras y canales institucionales y regionales"12. Los dividendos de la televisión digital TDT-, y la televisión directa al hogar (DTH) no pasan, en lo absoluto, por el texto de los acuerdos de paz. Se podría decir, en términos tecnológicos, que el acuerdo de paz suscrito entre el gobierno y las FARC-EP, es analógico y no digital.

Allí se puede apreciar que los conceptos utilizados en el texto del acuerdo no corresponden plenamente con las modalidades de los servicios de radio y de televisión, establecidas en la Resolución MINTIC 415 de $2010^{13}$, y en la Ley 182 de $1995^{14}$, respectivamente. Esas imprecisiones de orden técnico, además de demostrar un escaso conocimiento de las modalidades de prestación del servicio, y del régimen constitucional y legal de las comunicaciones en Colombia, puede generar dificultades a la hora determinar lo que efectivamente se pactó.

12 República de Colombia. Acuerdo final para la terminación de conflicto y la construcción de una paz estable y duradera. Gobierno de Colombia - FARC-EP. Bogotá. Noviembre 24 de 2016. Páginas 36 y 46. https://goo.gl/ZdtLYW

13 República de Colombia. Ministerio de Tecnologías de la Información y las Comunicaciones. MINTIC. Resolución 415 de 2010. Por la cual se expide el Reglamento de Radiodifusión Sonora y se dictan otras disposiciones. Tomado de: http://www.mintic.gov.co/portal/604/w3article-3797.html

${ }^{14}$ República de Colombia. Ley 182 de 1995. "Por la cual se reglamenta el servicio de la televisión y se formulan políticas para su desarrollo, se democratiza el acceso a éste, se conforman la Comisión Nacional de Televisión, se promueven la industria y actividades de televisión, se establecen normas para contratación de los servicios, se reestructuran entidades del sector y se dictan otras disposiciones en materia de telecomunicaciones". Tomado de: https://goo.gl/1E78ZC 
Para citar un ejemplo, según el texto del acuerdo de paz, en el numeral 2.2.1., las partes convinieron "Acceso a espacios en los canales y emisoras de interés público" ( $\mathrm{p}$. 43), como parte de las garantías para los movimientos y organizaciones sociales. Es deseable aclarar si el anterior acuerdo también compromete los espacios de las emisoras de interés público con las que cuentan las universidades públicas, y las emisoras de las fuerzas armadas, las cuáles son también clasificadas como de interés público.

Según lo anterior, legalmente hablando, y por cuanto en el texto del acuerdo suscrito se habla de "los canales de interés público", en plural. En consecuencia, se le deben asignar espacios a los movimientos y organizaciones sociales en el Canal UNO, por ser este un canal de interés público. Debe recordarse entonces que, este canal, lo licitó y entregó el Estado a particulares, mediante contrato suscrito en enero de 2016 ¿Qué paso con los espacios pactados?

En la letra menuda del asunto jurídico, se debe recordar que conforme el régimen legal dela televisión en Colombia, particularmente, la clasificación vigente establecida en el artículo 21 de la Ley 182 de 1995, el llamado Canal UNO, objeto de la Licitación Pública No. 01 de 2016, constituye un Canal de Interés Público, determinado y determinable. Respecto del Canal UNO, el Gobierno de Colombia se obligó, específicamente, en los compromisos suscritos en el "Acuerdo final para la terminación del conflicto y la construcción de una paz estable y duradera”.

En esa misma línea, en los acuerdos de paz se suscribió un compromiso para: "Abrir espacios en las emisoras y canales institucionales y regionales" (p. 218). Los canales regionales en Colombia son empresas industriales y comerciales del Estado que se asocian a empresas y entidades territoriales, además que se rigen por sus propios estatutos. ¿Tiene el gobierno nacional facultad para comprometer los espacios y los recursos de los operadores públicos regionales?

Por ahora, el gobierno y las FARC-EP, a instancias de la Autoridad Nacional de Televisión -ANTV-, el operador público RTVC, y un Comité de Comunicaciones Conjunto, tendrán por dos años, un espacio en el Canal Institucional, "con el fin de promover la convivencia, la reconciliación y la construcción de la paz"15. La asignación de este espacio se acompaña con el canal de televisión

${ }^{15}$ República de Colombia. Ministerio de Tecnologías de la Información y las Comunicaciones. MINTIC. Resolución 415 de 2010. Por la cual se expide el Reglamento de Radiodifusión Sonora y se dictan otras disposiciones. Tomado de: http://www.mintic.gov.co/portal/604/w3article-3797.html cerrada que se asignará a los partidos políticos. Quizás esta nueva propuesta televisiva logre romper el record de audiencia que el operador público, particularmente, el Canal Institucional, alcanzó en el desfile militar del 20 de julio de 2016.

Según RTVC: "El desfile militar del 20 de julio, en el que las Fuerzas Armadas rindieron homenaje al pueblo colombiano, fue el contenido más visto el pasado miércoles por los televidentes nacionales de la TV pública con un promedio de 258.870 personas, a través de la pantalla del Canal Institucional. (...) El de ayer fue el promedio diario más alto logrado por un canal de TV pública colombiana en lo que va del 2016, con cerca de 70.000 personas y el más alto del Canal Institucional en el mismo período" ${ }^{16}$.

En el texto del acuerdo, la expresión "tecnologías de la información y las comunicaciones" se utiliza en cuatro ocasiones para referirse a su acceso y uso en algunos proyectos puntuales del sector rural. Además, se habla de aplicaciones para telemedicina y biotecnología. No obstante, la negociación en términos de tecnologías de la información y las comunicaciones no es integral.

Prueba de lo anterior, es que el término "internet" solo es usado en dos ocasiones en el texto del acuerdo, para referirse a compromisos puntuales de "acceso a internet de alta velocidad en las cabeceras municipales" y la "oferta de soluciones de acceso comunitario a internet para centros poblados", pero, lo anterior, en el marco de "los planes Nacionales para la Reforma Rural Integral” (p. 23 $-25)$.

Desde otra perspectiva, el acuerdo no solo concede los espacios, además compromete al Estado en la financiación para la producción de contenidos audiovisuales y para la radiodifusión. Aun cuando en el texto del acuerdo se consignan diversas referencias a estrategias de comunicación y actividades de capacitación y de divulgación, se estima que los anteriores son los elementos más estructurales de la negociación.

\subsection{Coordenadas de acción estatal para la implementación de los acuerdos sobre comunicaciones.}

Para efectos de proceder a la implementación de los acuerdos suscritos en materia de comunicaciones, al igual que en otros sectores, tendrá que aceptarse que los

\footnotetext{
${ }^{16}$ República de Colombia. RTVC. Sistema de medios públicos. "Canal Institucional logra récord de audiencia en TV pública". 22 de Julio de 2016. Tomado de: https://www.rtvc.gov.co/noticia/canal-institucionallogra-record-de-audiencia-en-tv-publica
} 
compromisos adquiridos en 2016 nacieron al margen de lo previsto en el plan nacional de desarrollo en ejecución. Lo cual no quiere decir que algunos de los acuerdos no sean susceptibles de ejecutarse en el marco del referido plan.

Bajo esa orientación general, todos y cada uno de los compromisos adquiridos tienen que ser, razonablemente, delimitados para los efectos de poder estimar los costos. Por ejemplo: ¿Qué costos tiene crear e implementar un canal de televisión cerrada con destino a los partidos políticos? ¿Cuánto vale un día de operación de ese canal de televisión cerrada? Determinado el alcance de las acciones y los proyectos, así como los costos de los mismos, se podrá proceder a la elaboración de un plan con su correspondiente presupuesto plurianual y estrategia de financiación.

Los proyectos y los costos tendrán que trasladarse a las entidades que por competencia manejan los recursos del sector. El Fondo de Desarrollo de la Televisión y los Contenidos -FONTV-, y el Fondo de Tecnologías de la Información y las Comunicaciones del MINTIC tendrán que ser readecuados para el cumplimiento de los acuerdos. Los recursos del presupuesto nacional y de regalías serán otra alternativa.

El marco normativo para la actuación administrativa especial de los reguladores y de los operadores públicos de radio y televisión tendrá que ser readecuado para asumir el desarrollo de las nuevas tareas y para programar y ejecutar los recursos correspondientes. Los debates sobre el acceso de los partidos a los medios tendrán que ser asumidos en la Ley de los Partidos o en el Estatuto de la oposición.

La regulación de la pauta oficial tendrá que cruzar simultáneamente la Ley Anticorrupción, el Código Disciplinario, el Estatuto presupuestal, los planes de desarrollo, y la Ley de acceso a la información pública. Entre otros. Es incluso posible que algunas de las tensiones que generará la implementación de los acuerdos sobre comunicaciones tenga que resolverse mediante la modificación de la Ley 1341 de 2009 y el marco legal de la televisión, particularmente, la Ley 182 de 1995, la Ley 335 de 1996 y la Ley 1507 de 2012.

Sin duda, el hecho de que gran parte de las funciones del sector de tecnologías de la información y las comunicaciones se encuentren bajo el dominio del poder ejecutivo, será una ventaja para diseñar una estrategia para la implementación de los acuerdos sobre comunicaciones.

\section{Conclusiones}

Existen evidencias de que las demandas en materia comunicacional en Colombia se encuentran íntimamente ligadas a las causas del conflicto y el alzamiento armado. Desactivar tales causas y satisfacer las necesidades democráticas de comunicación en forma estructural garantiza una paz estable y duradera en materia de comunicaciones.

Los aspectos estructurales para la democratización de la comunicación en Colombia, tales como la creación de reguladores y operadores públicos independientes, así como los controles a la concentración de la propiedad, quedan para las negociaciones de un próximo acuerdo de paz o para una futura constituyente.

Los acuerdos logrados por las FARC-EP en materia de comunicaciones, aunque no son estructurales, contribuyen en buen grado a la democratización de la comunicación en Colombia.

Para la implementación de los acuerdos es urgente delimitar el alcance de los compromisos, establecer los costos, diseñar los planes, identificar las fuentes de financiación, así como disponer la estrategia adecuada para la ejecución.

El principio de colaboración armónica entre los reguladores y los operadores públicos podrá contribuir a la implementación de una estrategia idónea para materializar los acuerdos de paz sobre comunicaciones.

\section{Referencias}

1. Corredoira y Alfonso, 1. y Sánchez R. (2016). Qué es y qué no es derecho a la información. Dificultad metodológica de la consideración histórica de la información por la diversidad de sus parámetros de observación. En Corredoira y Alfonso, 1., Sánchez, R. y Gutiérrez, f. (Eds.) Informar. ¿Derecho o deber? ¿De qué hablamos cuando hablamos del derecho a informar? (68-134). IAMCR conference. fiédi - leicester2016. Universidad Complutense de Madrid. Madrid. España. Disponible en: http:// eprints.ucm.es/39990/

2. FARC-EP. (1993). Octava conferencia nacional de guerrilleros. "plataforma de un gobierno de reconstrucción y reconciliación nacional". 3 de 
abril de 1993. Tomado de: http://www.farc-ep.co/ octava-conferencia/plataforma-de-un-gobiernode-reconstruccion-y-reconciliacion-nacional.html

3. FARC-EP. (2017). Tesis preparatorias del congreso fundacional del partido de las FARCEP - marzo de 2017. tomado de: https://es.scribd. com/document/345997569/farc-ep-por-unpartido-para-construir-la-paz-y-la-perspectivademocratico-popular

4. FECOLPER - Reporteros sin fronteras de Alemania. (2015). Monitoreo de la propiedad de medios. mom - media ownership monitor. Bogotá D.C. publicado en: http://www.monitoreodemedios.co/gruposmediaticos/

5. Garzón Barreto, J. C. (2015). Televisión y Estado en Colombia 1954 - 2014. Cuatro momentos de intervención del Estado. Editorial Universidad Externado de Colombia. Bogotá, Colombia.

6. Garzón Barreto,J.C.(2017a)¿Quéesloquereivindican hoy los defensores acríticos de la libertad de prensa? publicado en: http://juancarlosgarzonbarreto. blogspot.com.co/2017/05/dia-mundial-de-lalibertad-de-prensa.html

7. Garzón Barreto, J. C. (2017b). Colombia: transformaciones de lo comunicacional $y$ reconfiguración del derecho de la comunicación. Ponencia presentada al congreso de la asociación internacional de estudios en comunicación social. IAMCR/AIECS 2017. Cartagena - Colombia. Julio de 2017.

8. Garzón Barreto, J. C. y Neira Parra Ingrid. (2017). Panorama de las leyes y políticas de comunicación en Colombia en la última década. Las principales coordenadas históricas de la libertad de expresión en el constitucionalismo colombiano. En proceso de edición - Universidad Nacional de Colombia.

9. Gómez Gallego, J. A., Herrera Vergara, J. R., y Pinilla Pinilla, N. (2010). Informe final de la comisión de la verdad sobre los hechos del palacio de justicia. Universidad Colegio Mayor de Nuestra Señora del Rosario. Bogotá, Colombia.

10. Medina Gallego, C. (2012). ELN Ejército de Liberación Nacional. Notas para una historia de las ideas políticas. (1958-2007). Universidad Nacional de Colombia. Facultad de Ciencias Humanas. Departamento de Historia. Programa de Doctorado. tomado de:https://observatoriodelapazencolombia. files.wordpress.com $/ 2012 / 11 /$ medina-gallegocarlos-e-l-n-notas-para-una-historia-de-las-ideaspoliticas-1958-2007.pdf

11. Miterrand, F. (1988) "carta a los franceses". Disponible en: http://miroirs.ironie.org/socialisme/ www.psinfo.net/entretiens/mitterrand/1988lettre. $\underline{\mathrm{html}}$

12. Molano Camargo, F. (2015) Los orígenes del partido comunista marxista-leninista de Colombia y del Ejército de Liberación Popular - EPL. Rebelión. Disponible en: https://goo.gl/t4vbmn

13. Movimiento Obrero Estudiantil Campesino 7 de enero -MOEC- (1965). Hagamos del MOEC un auténtico partido marxista leninista. Comunicado. 1 de Octubre de 1965. Disponible en: https://goo. $\mathrm{gl} / \mathrm{zjk} 6 \mathrm{px}$

14. Partido Comunista Marxista-leninista de Colombia (2007). XVI Congreso. Línea nacional. Primera parte. La formación económico-social de Colombia. Disponible en https://goo.gl/jqczy3

15. República de Colombia. Acuerdo final gobierno nacional - Ejército Popular de Liberación. Febrero 15 de 1991. Disponible en: http://www.cedema.org/ uploads/acuerdo_epl.pdf

16. República de Colombia. Acuerdo final para la terminación del conflicto y la construcción de una paz estable y duradera. Gobierno de Colombia - FARCEP. Bogotá. Noviembre 24 de 2016. Disponible en: https://goo.gl/zdtlyw

17. República de Colombia. Corte Constitucional. Sentencia C-350 de $1997 . \quad$ http://www.corteconstitucional. gov.co/relatoria/1997/c-350-97.htm

18. República de Colombia. Ley 182 de 1995. Por la cual se reglamenta el servicio de la televisión y se formulan políticas para su desarrollo, se democratiza el acceso a éste, se conforman la comisión nacional de televisión, se promueven la industria y actividades de televisión, se establecen normas para contratación 
de los servicios, se reestructuran entidades del sector y se dictan otras disposiciones en materia de telecomunicaciones. Disponible en: https://goo. $\mathrm{gl} / 1 \mathrm{e} 78 \mathrm{zc}$

19. República de Colombia. Ministerio de Tecnologías de la Información y las Comunicaciones - MINTIC -. Resolución 415 de 2010. Por la cual se expide el reglamento de radiodifusión sonora y se dictan otras disposiciones. Disponible en: http://www. mintic.gov.co/portal/604/w3-article-3797.html

20. República de Colombia. Ministerio de Tecnologías de la Información y las Comunicaciones - MINTIC. Resolución 415 de 2010. Por la cual se expide el reglamento de radiodifusión sonora y se dictan otras disposiciones. Disponible en: http://www.mintic. gov.co/portal/604/w3-article-3797.html

21. República de Colombia. RTVC - Sistema de medios públicos. Canal institucional logra récord de audiencia en TV pública. 22 de julio de 2016. Tomado de: https://www.rtvc.gov.co/noticia/canalinstitucional-logra-record-de-audiencia-en-tvpublica

22. Revista Semana. El comunicado y las exigencias del M-19. 12 de Diciembre de 1985. Disponible en: http://www.semana.com/especiales/articulo/el- comunicado-las-exigencias-del-m-19/7191-3.

23. Revista Semana. La venganza gaitanista. 21 de agosto 21 de 1989. Disponible en: http://www. semana.com/nacion/articulo/la-venganzagaitanista/12156-3

24. Rojas, E. (1987). Notas de comandancia sobre la historia del EPL. Disponible en: https://goo. gl/7wl5lw

25. Villarraga Sarmiento, A. (s.f.) El Ejército Popular de Liberación. EPL. Presentación. Centro nacional de memoria histórica. Disponible en: http:// centrodememoriahistorica.gov.co/descargas/ catedraby/presentaciones/sesion-4/presentacionepl.pdf 